\title{
Coincidence of Genetic Loci for Plasma Cholesterol Levels and Obesity in a Multifactorial Mouse Model
}

Craig H. Warden, Janis S. Fisler, Mario J. Pace, Karen L. Svenson, and Aldons J. Lusis

Department of Medicine, Department of Microbiology and Molecular Genetics, and Molecular Biology Institute, University of California Los Angeles, California 90024

\begin{abstract}
We have examined backcross progeny derived from a cross of Mus spretus with C57BL/6J, that range from 1 to $50 \%$ carcass lipid $(n=215)$, and from 22 to $130 \mathrm{mg} / \mathrm{dl}$ plasma total cholesterol $(n=238)$. Statistical analysis revealed that distal mouse chromosome 7 exhibits significant linkage both to plasma total cholesterol (likelihood of the odds [LOD] 5.8) and to carcass lipid (LOD 3.8). A locus on chromosome 6 also shows significant linkage to plasma total cholesterol (LOD 5.6), but no linkage to carcass lipid. Neither chromosomal region contains any previously mapped genes likely to influence lipoprotein metabolism, indicating that novel genetic factors contributing to plasma lipoprotein levels have been identified. (J. Clin. Invest. 1993. 92:773-779.) Key words: lipoproteins • cholesterol • obesity $\bullet$ genetics $\bullet$ linkage (genetics)
\end{abstract}

\section{Introduction}

Atherosclerosis, the cause of coronary artery disease (CAD), ${ }^{1}$ is a complex disorder with important genetic as well as environmental contributions. Our understanding of the genetics of the disease is largely derived from analysis of various relatively rare genetic syndromes, such as familial hypercholesterolemia, and from genetic studies of "candidate genes" identified in biochemical studies $(1,2)$. However, the general analysis of multigenic traits, including atherosclerosis and most of its risk factors, is difficult directly in humans. On the other hand, methods for analysis of multigenic and polygenic traits have been developed for inbred animal models $(3,4)$. These methods have recently been used to identify chromosomal loci in rodents contributing to two important CAD risk factors, diabetes $(5)$, and hypertension $(6,7)$. We now report the identification of novel chromosomal loci contributing to two additional CAD risk factors, lipoprotein levels and obesity, in a new multifactorial mouse model.

In contrast to other CAD risk factors, a number of genes, encoding apolipoproteins, lipoprotein receptors, and enzymes mediating lipid metabolism, are now known to contribute to

Address correspondence to Dr. Craig Warden, Division of Cardiology, Department of Medicine, UCLA Medical Center, 10833 Le Conte Avenue, Los Angeles, CA 90024.

Received for publication 4 January 1993 and in revised form 19 March 1993.

1. Abbreviations used in this paper: CAD, coronary artery disease; LOD, likelihood of the odds; QTL, quantitative trait locus.

J. Clin. Invest.

(c) The American Society for Clinical Investigation, Inc.

0021-9738/93/08/0773/07 \$2.00

Volume 92, August 1993, 773-779 variations in lipoprotein levels $(1,2)$. Nevertheless, these genetic factors account for a small fraction of the interindividual variance of lipoprotein levels; for example, the genetic determinants of HDL, which are strongly inversely correlated with risk of CAD, are largely unknown $(2,8,9)$. It appears likely that novel genetic factors, not yet identified as candidate genes through biochemical approaches, participate in the genetic control of lipoprotein metabolism.

Univariate regression analyses have shown that obesity is a predictor of CAD (10). The risk of developing CAD is increased twofold in people who are $40 \%$ or more overweight (11). However, multivariate analyses correcting for plasma cholesterol, as well as for other traits, suggest that obesity is not an independent predictor of CAD (12-17). Several monogenic rodent models with obesity (18-21) have been identified, and are being pursued by positional cloning. However, little is known about the genetic basis of obesity in the multifactorial models that have been described $(22,23)$. Furthermore, even for monogenic models of obesity, the specific gene underlying obesity is currently known only for the agouti locus that is responsible for the lethal and viable yellow mutations (24). Several studies have shown that plasma cholesterol levels are positively correlated with obesity in rodent models. For example, mice with the obese/obese $(o b / o b)$ genotype have increased total and HDL cholesterol levels (25) and the LA/Ncp rats are obese and have elevated plasma cholesterol and triglyceride levels (26).

The development of highly polymorphic genetic markers that can be genotyped by PCR (27-29) and new statistical methods $(30,31)$ have made it practical to analyze quantitative multifactorial traits in inbred animal models $(3,4)$. The approach involves typing of backcross or F2 progeny for the trait of interest and for genetic markers spanning the genome. Statistical analyses, such as chi square analysis or log likelihood analysis, are then used to identify genetic loci contributing to the multigenic trait $(3,30,31)$.

We introduce here a new mouse model of multigenic obesity and lipoprotein metabolism involving progeny of a cross between Mus spretus (Spretus) and C57BL/6J (32). The backcross progeny have been useful for the identification of quantitative trait loci contributing to plasma cholesterol levels and obesity.

\section{Methodology}

Genetic crosses. Breeding pairs of Mus musculus domesticus (C57BL/ $6 \mathrm{~J}$ ) were obtained from The Jackson Laboratory (Bar Harbor, ME) and Mus spretus (Spain) were obtained from Dr. Michael Potter (National Institutes of Health, Bethesda, MD). A backcross was performed by crossing $\mathrm{F} 1$ females, resulting from the cross of female C57BL/6J with male $M$. spretus mice, with male $\mathrm{C} 57 \mathrm{BL} / 6 \mathrm{~J}$ mice. We have designated these backcross progeny as BSB mice. After weaning at $21 \mathrm{~d}$, mice were individually housed in plastic cages with free access to food and water throughout the experimental period. Mice were fed standard 
commercial rodent chow containing $12 \%$ of calories as fat from weaning throughout the study ( $n=104$ females, 96 males) or were maintained on a moderate fat, high cholesterol diet (Teklad 90221; Teklad Premier Laboratory Diets, Madison, WI) containing 30\% of calories as fat for 5 wk ( $n=43$ females, 24 males) before killing (33). Regular 12-h light and dark cycles were maintained in a room with a temperature of $22^{\circ} \mathrm{C}$.

Quantitative phenotype measurements. Mice were fasted for $\sim 15 \mathrm{~h}$ before transport to the laboratory and collection of blood through the retroorbital sinus within $90 \mathrm{~s}$ of initiating ether anesthesia at $\sim 3 \mathrm{~h}$ into the light phase of the diurnal cycle. Blood samples were collected in plasma separator tubes containing EDTA, placed on ice, and centrifuged to prepare plasma.

Plasma total and HDL cholesterol, triglyceride, and glycerol concentrations were determined by enzymatic procedures employing colorimetric endpoints. All assays were run in 96-well microtiter plates using a Biomek 1000 Automated Laboratory Workstation (Beckman Instruments, Inc., Carlsbad, CA). Samples were diluted with saline so that their measured absorbance values were in the linear range of established standard curves. Each sample was measured in quadruplicate. An external control sample with a known analyte concentration was run in each plate to assure accuracy. Triglyceride and glycerol were measured by a modification of a previously published method (34) using a kit (GPO-Trinder, procedure 337; Sigma Immunochemicals, St. Louis, MO). All reaction volumes were scaled down from recommended levels so that the entire reaction might be run in a microtiter well. Absorbances were measured using a $V_{\max }$ plate reader (Molecular Devices, Eugene, Oregon) at $510 \mathrm{nM}$ for triglyceride and glycerol. Plasma total and HDL cholesterol concentrations were determined by enzymatic procedures employing colorimetric endpoints as described previously (35). LDL plus VLDL cholesterol was calculated by difference (total - HDL cholesterol).

Body mass index was calculated as body weight $(\mathrm{g})$ divided by the square of the anal-nasal length $(\mathrm{cm})$. Three intrabdominal fat pads, the retroperitoneal, mesenteric, and epididymal (male) or parametrial (female) fat pads were dissected, weighed, and returned to the carcass. A subcutaneous fat pad lying over the outer thigh (femoral) was also dissected, weighed, and returned to the carcass. Body composition was based on the carcass remaining after removal of the liver, kidneys, and spleen for DNA isolation. The carcass was dried to constant weight at $90^{\circ} \mathrm{C}$, homogenized, and aliquots taken for extraction of lipid in a Soxhlet apparatus (Nos. 09-585 and 09-678; Fisher Scientific, Pittsburgh, PA). Lipid was determined gravimetrically and expressed as percent wet tissue weight. These data are reported in (32).

Genotyping. Genomic DNA was isolated from spleen and kidneys by treatment with SDS and proteinase $\mathrm{K}$ followed by phenol-chloroform extraction as previously described (36). Southern blot analysis was performed by subjecting 5- $\mu \mathrm{g}$ samples of each DNA from parental or backcross mice to restriction enzyme digestion, electrophoresis on $1 \%$ agarose gels, transfer to nylon filters, and cross-linking by ultraviolet irradiation. Filters were then hybridized under standard conditions with cDNA inserts labeled to a specific activity by $\sim 1 \times 10^{9} \mathrm{cpm} / \mu \mathrm{g}$ by random priming with $\left[{ }^{32} \mathrm{P}\right] \mathrm{CTP}$ and Klenow polymerase (BRL, Gaithersburg, MD). Prehybridization and hybridization of the nitrocellulose and probes were carried out at $65^{\circ} \mathrm{C}$ in $0.5 \mathrm{M}$ sodium phosphate buffer, $\mathrm{pH} 7.0,1 \mathrm{mM}$ EDTA, $7 \%$ SDS, and $0.1 \%$ bovine plasma albumin while being shaken (37). After the hybridization, the filters were washed once with $1 \times \mathrm{SSC}\left(1 \times \mathrm{SSC}\right.$ is $0.15 \mathrm{M} \mathrm{NaCl}, 15 \mathrm{mM} \mathrm{Na}_{3}$ citrate, $\mathrm{pH} 7.0$ ) at room temperature and twice with $0.1 \times \mathrm{SSC}, 0.1 \%$ SDS at $65^{\circ} \mathrm{C}$. The filters were dried and exposed to Kodak x-ray film for autoradiography.

D7Ucla 1 is a randomly isolated mouse liver cDNA clone from a $\lambda$ ZAP library (Warden, C. H., M. Mehrabian, K.-Y. He, M. Y. Yoon, A. Diep, Y.-R. Xia, P. Z. Wen, K. L. Svenson, R. S. Sparkes, and A. J. Lusis, unpublished data). When mouse genomic DNA was digested with EcoRI the D7Uclal probe hybridized to $12-, 4.7-$, and $2.1-\mathrm{kb}$ restriction fragments from $\mathrm{C} 57 \mathrm{BL} / 6 \mathrm{~J}$, and to $7.2-$ and 3.6-kb restriction fragments from Mus spretus. The Mus spretus 7.2-kb fragment revealed by D7Uclal was mapped to chromosome 7 and is the restriction fragment length variant (RFLV) used for this report. The 3.6-kb restriction fragment mapped to the mouse $\mathrm{X}$ chromosome. The Apoe gene was typed as previously described (36) using a HindIII RFLV. Simple sequence length variants were detected by polymerase chain reaction as described previously (29).

Data analysis. The quantitative trait locus (QTL) mapping method was used as described (3). Linkage analysis of the polymorphisms found for each locus was performed with the MAPMAKER program (30), with genetic distances reported as recombination fraction. The MAPMAKER/QTL program (provided by S. Lincoln and E. Lunder, Massachusetts Institute of Technology) was used for QTL analysis as described for F2 backcrosses (31). Progeny were divided into male and female groups to detect possible differences due to sexual dimorphism. Levels of significance $(P)$ and age adjusted values were calculated with the StatView and SuperANOVA programs (Abacus Concepts, Inc., Berkeley, CA) on the Macintosh.

\section{Results}

Correlation of plasma cholesterol levels with obesity in a new mouse model of multifactorial obesity. Plasma cholesterol levels are higher in Mus spretus than in C57BL/6J mice. The mean \pm SE values measured in seven female Mus spretus and 15 female C57BL/6J are, respectively: total cholesterol, 132 \pm 9.4 $\mathrm{mg} / \mathrm{dl}$ vs. $75 \pm 2.3(P<0.0001)$; HDL cholesterol, $101 \pm 6.7$ vs. $48 \pm 1.3(P<0.0001)$; LDL plus VLDL cholesterol, $31 \pm 3.5$ vs. $26 \pm 1.8(P>0.05)$. Since their total and HDL cholesterol levels differ almost twofold, we performed a backcross with C57BL/ $6 \mathrm{~J}$ and Mus spretus as parental strains ([C57BL/6J $\times$ Mus spretus $] \times \mathrm{C} 57 \mathrm{BL} / 6 \mathrm{~J})$ to identify quantitative trait loci underlying plasma cholesterol levels. We designated the backcross progeny as BSB mice. During the course of these studies, we observed varying degrees of obesity among backcross animals, although both parental strains are relatively lean. Backcross progeny range from 1 to $50 \%$ carcass lipid (Fig. 1$)(n=215)$, from 22 to $130 \mathrm{mg} / \mathrm{dl}$ plasma total cholesterol on a chow diet (Fig. 1) $(n=238)$, and from $0.02 \mathrm{~g}$ to $3.3 \mathrm{~g}$ for subcutaneous (femoral) fat $(n=92)$. The correlations (Spearman's rho) of the four measured fat pads and carcass lipid percentage with total cholesterol range from 0.29 (subcutaneous) to 0.54 (mesenteric) in females and from 0.26 (carcass lipid) to 0.38 (retroperitoneal) in males (Table I). The correlations of plasma triglyceride levels with the four fat pads or with carcass lipid percentage range from 0.08 (subcutaneous) to 0.52 (parametrial) in females and from 0.25 (subcutaneous) to 0.55 (mesenteric) in males (Table I). These results clearly indicate that the measures of obesity can, to some extent, vary independently in BSB mice. Whereas it has been reported that $o b / o b$ mice have elevated levels of total and HDL cholesterol (25), the BSB backcross mice provide an opportunity to study the linkage of plasma cholesterol levels with obesity in a multifactorial mouse model.

Loci on mouse chromosome 7 for plasma total cholesterol and for the percentage of carcass lipid. We have identified quantitative trait loci underlying plasma total cholesterol levels and quantitative measures of obesity by genotyping the BSB mice with RFLVs of cDNA clones and with simple sequence length variants. A subset of the animals was typed for 242 genetic markers, including all mouse chromosomes, and all of the animals were typed for at least 67 widely dispersed markers. We searched for genetic loci underlying quantitative traits in BSB backcross mice using the program MAPMAKER/QTL (31). The strength of association between genotypes at each 


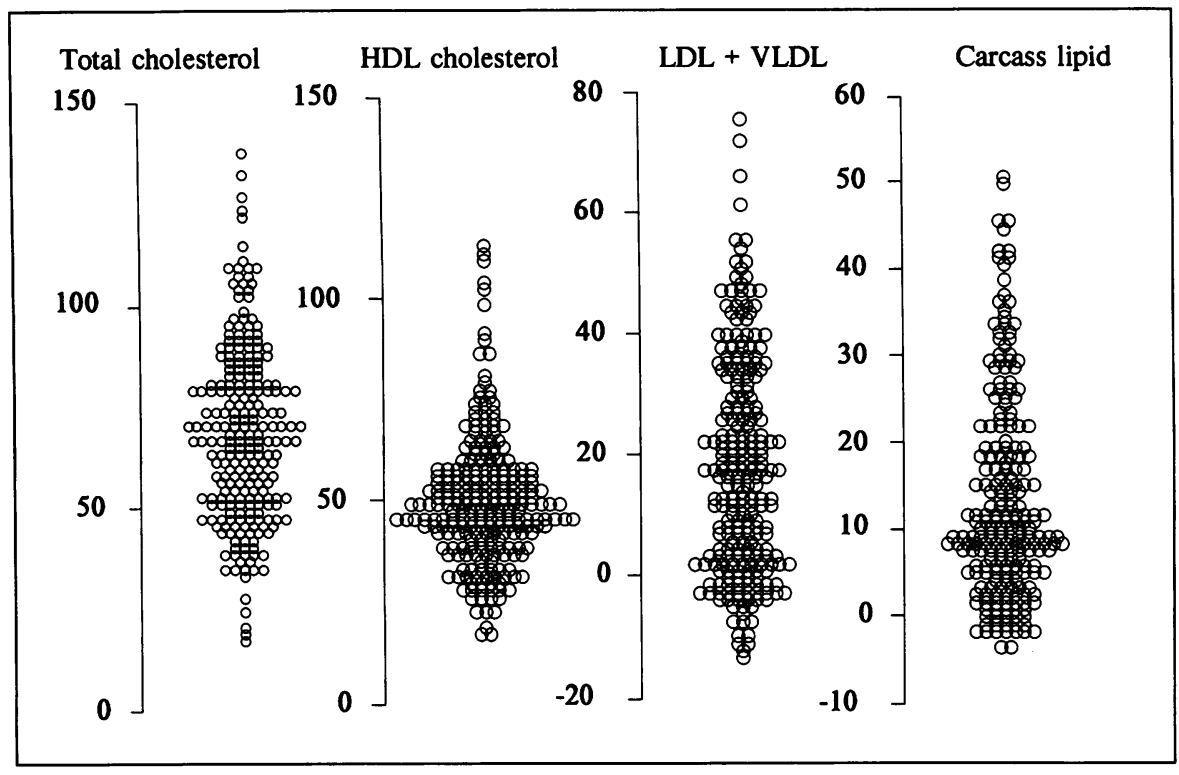

Figure 1. Age adjusted values for total, HDL, and LDL + VLDL (expressed as milligrams per deciliter) cholesterol and carcass lipid (percentage of carcass weight as lipid) among BSB mice. The levels of LDL + VLDL were calculated by subtraction of HDL from total cholesterol; the values less than zero result from assay error. Values less than zero for carcass lipid are due to linear correction for age. locus and the phenotype under investigation is expressed as a $\log _{10}$ of the likelihood of the odds ratio (LOD) score.

A locus for plasma total cholesterol levels (Chol-1) was observed on distal mouse chromosome 7 , with a peak LOD score of 5.8 at the D7Uclal locus (Fig. 2). This locus accounts for $\sim 10 \%$ of the variance of total cholesterol in the BSB mice. Mice that have the "SB" genotype (heterozygous for Mus spretus and C57BL/6J alleles) at the D7Uclal locus have a $20 \%$ increase of total cholesterol levels compared with mice that are "BB" (homozygous for C57BL/6J alleles) at that locus $(P$ $<0.0001$ ) (Table II). Whereas both male and female mice with the SB genotype have increased total cholesterol levels, males are more affected by the underlying locus than are females
(Table III). Males have a peak LOD score of 4.3 (accounting for $17 \%$ of variance), while females have a peak LOD score of 1.4 (accounting for $5 \%$ of variance) at the D7Uclal locus. We designate this locus as Chol-1, for cholesterol-1. Although HDL cholesterol accounts for $80-90 \%$ of total cholesterol of mice on a chow diet, in male mice the Chol- 1 locus has an even larger percentage effect on the LDL + VLDL cholesterol than on HDL cholesterol levels (Table III). Thus, Chol-1 appears to affect total plasma cholesterol levels, rather than specifically affecting HDL or LDL + VLDL levels.

A locus for multigenic obesity, designated $M o b-1$, occurs in precisely the same distal region of mouse chromosome 7, with a peak LOD score of 3.8 at the D7Uclal locus (Fig. 2). On

Table I. Strength of Association, Expressed as Spearman's rho, between Quantitative Measures of Obesity and Plasma Cholesterol Levels in the BSB Mice

\begin{tabular}{|c|c|c|c|c|c|c|c|c|c|c|c|}
\hline & $\begin{array}{c}\text { Total } \\
\text { cholesterol }\end{array}$ & HDL & VLD + LDL & Triglycerides & $\begin{array}{c}\text { Body } \\
\text { weight }\end{array}$ & $\begin{array}{l}\text { Body } \\
\text { mass } \\
\text { index }\end{array}$ & $\begin{array}{l}\text { Carcass } \\
\text { lipid }\end{array}$ & Subcutaneous & Mesenteric & $\begin{array}{l}\text { Epididymal/ } \\
\text { parametrial }\end{array}$ & Retroperitoneal \\
\hline Total cholesterol & & 0.62 & 0.68 & 0.44 & 0.39 & 0.23 & 0.50 & 0.29 & 0.54 & 0.45 & 0.48 \\
\hline HDL cholesterol & 0.83 & & -0.08 & 0.22 & 0.43 & 0.45 & 0.39 & 0.45 & 0.56 & 0.60 & 0.63 \\
\hline $\begin{array}{l}\text { VLDL plus LDL } \\
\text { cholesterol }\end{array}$ & 0.49 & -0.01 & & 0.37 & 0.10 & -0.07 & 0.33 & 0.04 & 0.30 & 0.07 & 0.09 \\
\hline Triglycerides & 0.52 & 0.39 & 0.44 & & 0.33 & 0.20 & 0.49 & 0.08 & 0.41 & 0.52 & 0.48 \\
\hline Body weight & 0.29 & 0.34 & 0.02 & 0.39 & & 0.72 & 0.59 & 0.61 & 0.79 & 0.81 & 0.76 \\
\hline Body mass index & 0.42 & 0.45 & 0.02 & 0.51 & 0.90 & & 0.47 & 0.50 & 0.76 & 0.80 & 0.80 \\
\hline Carcass lipid & 0.26 & 0.20 & 0.20 & 0.45 & 0.74 & 0.60 & & 0.74 & 0.67 & 0.87 & 0.85 \\
\hline Subcutaneous & 0.31 & 0.26 & 0.13 & 0.25 & 0.75 & 0.68 & 0.78 & & 0.62 & 0.81 & 0.74 \\
\hline Mesenteric & 0.28 & 0.34 & 0.27 & 0.55 & 0.75 & 0.78 & 0.62 & 0.69 & & 0.75 & 0.68 \\
\hline $\begin{array}{l}\text { Epididymal/ } \\
\text { parametrial }\end{array}$ & 0.27 & 0.30 & 0.07 & 0.48 & 0.87 & 0.84 & 0.85 & 0.75 & 0.72 & & 0.88 \\
\hline Retroperitoneal & 0.37 & 0.40 & 0.14 & 0.52 & 0.86 & 0.84 & 0.86 & 0.81 & 0.81 & 0.90 & \\
\hline
\end{tabular}

Values to the left of the diagonal are Spearman rank correlation coefficients (rho) for males and values to the right of the diagonal are correlation coefficients for female calculated for pairs of traits associated with obesity for all BSB backcross mice. Sample sizes are: total plasma cholesterol (151 males, 171 females); HDL cholesterol (151 males, 171 females); total - HDL cholesterol (151 males, 171 females); body wt (151 males, 171 females) body mass index ( 151 males, 171 females); carcass lipid ( 143 males, 145 females); epididymal/parametrial fat pads (100 males, 92 females); retroperitoneal fat pad ( 100 males, 92 females); mesenteric fat pad ( 100 males, 92 females); subcutaneous (femoral) fat pad ( 73 males, 72 females). 


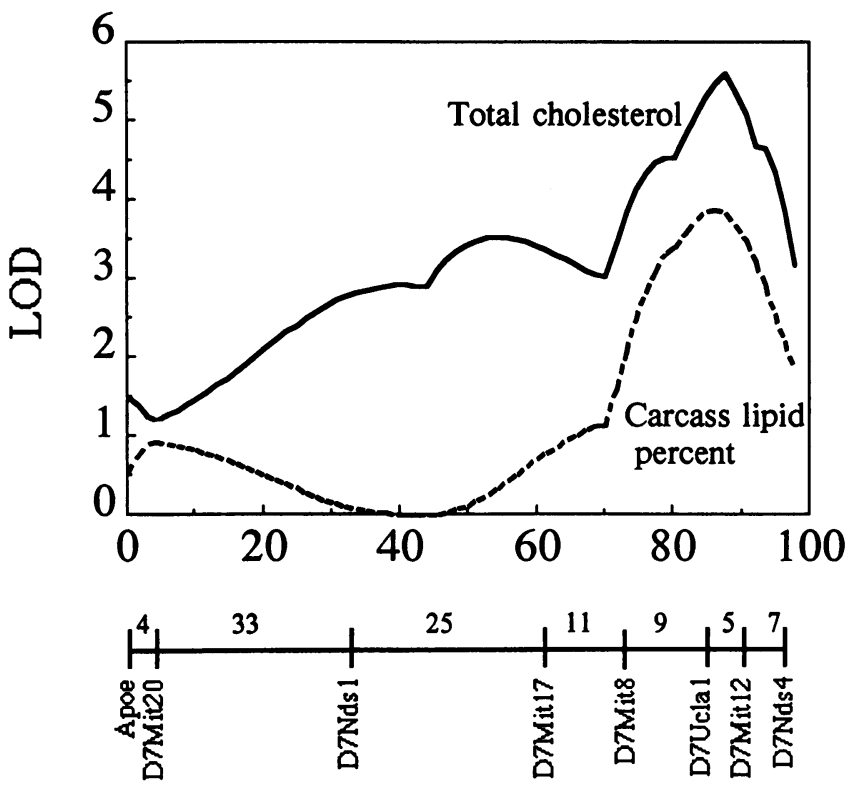

\section{Centimorgans}

Figure 2. LOD likelihood plot for plasma cholesterol levels and carcass lipid percent, adjusted for a linear effect of age, on chromosome 7. D7Mit20, D7Nds1, D7Mit17, D7Mit12, D7Nds4, and D7Mit8 are simple sequence length variants (29). The $y$ axis shows the LOD score calculated by the MAPMAKER/QTL program at 2-centimorgan intervals. The $x$ axis shows the genetic distances of markers in centimorgans. All eight loci are linked to each other with log likelihood scores of at least 5 . The order of these markers is supported by odds ratios of at least 100:1. The position of D7Uclal between D7Mit8 and D7Mit 12 is supported by an odds ratio $>1,000: 1$. average, mice with the SB genotype at the D7Uclal locus have $\sim 50 \%$ more carcass lipid than mice with the BB genotype ( $P$ $<0.0002$ ) (Table II). The Mob-1 locus has approximately equal effects on males and females (Table III). The LOD scores for males and females at the D7Uclal locus are, respectively, 1.6 and 2.2. The effects of the quantitative trait loci on measures of obesity are not confined to carcass lipid percent. The D7Uclal locus has strongly suggestive correlations with the four measured fat pads. Both mesenteric and retroperitoneal fat pads exhibit $P$ values of 0.001 at the D7Uclal locus, for comparison of the two genotypes in the BSB mice, when analyzed by ANOVA (Table II). Epididymal / parametrial and subcutaneous fat pads have less significant, but suggestive, correlations at the D7Uclal locus (Table II). Thus, the locus underlying $M o b-1$ appears to simultaneously affect several different measures of obesity.

Loci on chromosome 6 for plasma total cholesterol and a subcutaneous fat pad. A locus for plasma total cholesterol levels (Chol-2) is found on proximal mouse chromosome 6, with a peak LOD score of 5.6 at the D6Mit1 locus. This locus accounts for $8 \%$ of the variance of plasma total cholesterol in the BSB mice. Mice with the SB genotype have an $18 \%$ increase in total cholesterol levels compared with mice that are BB at the D6Mit1 locus $(P<0.0001)$ (Table II). Whereas both male and female mice with the SB genotype at the D6Mitl locus have increased total cholesterol levels, as also seen at the D7Uclal locus, males are more affected by the underlying locus than are females (Table IV) and the Chol-2 locus has a larger percentage effect on LDL plus VLDL cholesterol of BSB mice than on HDL cholesterol levels (Table IV).

A strongly suggestive locus for a subcutaneous fat pad $(M o b-2)$, the femoral depot, occurs at the D6Mit1 locus of

Table II. Comparison of Plasma Cholesterol, Carcass Fat, and Fat Pad Weights by Genotype at Selected Markers

\begin{tabular}{|c|c|c|c|c|}
\hline \multirow[b]{2}{*}{ Phenotype } & \multirow[b]{2}{*}{ Marker } & \multicolumn{2}{|c|}{ Statistics by genotype } & \multirow{2}{*}{$\begin{array}{l}\text { ANOVA } \\
\text { All data }\end{array}$} \\
\hline & & BB & SB & \\
\hline \multirow[t]{6}{*}{ Total cholesterol (mg/dl) } & D7Uclal & $63 \pm 1.6$ & $75 \pm 1.8$ & $P<0.0001$ \\
\hline & & $n=121$ & $n=96$ & \\
\hline & D7Mit8 & $64 \pm 1.8$ & $77 \pm 2.0$ & $P<0.0001$ \\
\hline & & $n=102$ & $n=81$ & \\
\hline & D6Mitl & $63 \pm 1.7$ & $74 \pm 1.8$ & $P<0.0001$ \\
\hline & & $n=115$ & $n=103$ & \\
\hline \multirow[t]{4}{*}{ Carcass lipid (\%) } & D7Uclal & $12 \pm 0.9$ & $17 \pm 1.0$ & $P<0.0002$ \\
\hline & & $n=113$ & $n=96$ & \\
\hline & D7Mit8 & $12 \pm 1.0$ & $17.7 \pm 1.1$ & $P<0.0006$ \\
\hline & & $n=96$ & $n=78$ & \\
\hline \multirow[t]{2}{*}{ Mesenteric fat pad (g) } & D7Ucla1 & $0.28 \pm 0.04$ & $0.46 \pm 0.04$ & $P<0.001$ \\
\hline & & $n=74$ & $n=61$ & \\
\hline \multirow[t]{2}{*}{ Retroperitoneal fat pads (g) } & D7Uclal & $0.10 \pm 0.02$ & $0.23 \pm 0.03$ & $P<0.001$ \\
\hline & & $n=74$ & $n=61$ & \\
\hline \multirow{2}{*}{$\begin{array}{l}\text { Epididymal or Parametrial } \\
\text { fat pads }(\mathrm{g})\end{array}$} & D7Ucla1 & $0.57 \pm 0.10$ & $1.0 \pm 0.11$ & $P<0.004$ \\
\hline & & $n=74$ & $n=61$ & \\
\hline \multirow[t]{4}{*}{ Subcutaneous fat pads (g) } & D7Uclal & $0.34 \pm 0.09$ & $0.75 \pm 0.10$ & $P<0.003$ \\
\hline & & $n=49$ & $n=39$ & \\
\hline & D6Mit1 & $0.29 \pm 0.09$ & $0.75 \pm 0.10$ & $P<0.0009$ \\
\hline & & $n=52$ & $n=38$ & \\
\hline
\end{tabular}


Table III. Comparison of Plasma Cholesterol and Carcass Lipid at the D7Uclal Locus in Male and Female BSB Mice

\begin{tabular}{|c|c|c|c|c|}
\hline \multirow[b]{2}{*}{ Trait } & \multicolumn{2}{|c|}{ Statistics by genotype, males } & \multicolumn{2}{|c|}{ Statistics by genotype, females } \\
\hline & BB & SB & BB & SB \\
\hline \multirow[t]{2}{*}{ Total cholesterol (mg/dl) } & $63 \pm 2.4$ & $82 \pm 2.6^{*}$ & $63 \pm 2.1$ & $69 \pm 2.5$ \\
\hline & $n=56$ & $n=46$ & $n=65$ & $n=50$ \\
\hline \multirow[t]{2}{*}{ HDL cholesterol (mg/dl) } & $49 \pm 2.1$ & $61 \pm 2.3^{*}$ & $45 \pm 2.0$ & $49 \pm 2.2$ \\
\hline & $n=56$ & $n=46$ & $n=65$ & $n=50$ \\
\hline \multirow[t]{2}{*}{ LDL + VLDL cholesterol (mg/dl) } & $14 \pm 1.6$ & $21 \pm 1.8$ & $18 \pm 1.5$ & $20 \pm 1.7$ \\
\hline & $n=56$ & $n=46$ & $n=65$ & $n=50$ \\
\hline \multirow[t]{2}{*}{ Carcass lipid (\%) } & $12 \pm 1.4$ & $18 \pm 1.5^{\ddagger}$ & $11 \pm 1.3$ & $16 \pm 1.4^{\ddagger}$ \\
\hline & $n=54$ & $n=44$ & $n=59$ & $n=52$ \\
\hline
\end{tabular}

Data are age adjusted means \pm SE. ANOVA: $\mathrm{SB}$ versus $\mathrm{BB},{ }^{*} P<0.0001,{ }^{\ddagger} P<0.009$.

chromosome 6 , with a peak LOD score of 2.8. While this locus accounts for $16 \%$ of the variance of the femoral fat pad in the BSB mice, those mice with the SB genotype at the D6Mit1 locus have $\sim 2.5$-fold larger femoral fat pads than mice with the BB genotype $(P<0.0009)$ (Table II). The Mob-2 locus affects males and females about equally (Table IV). This association is specific to the subcutaneous fat pad, as carcass lipid percent and the other three fat pads are not different at the D6Mit1 locus $(P>0.01)$. The Chol-2 and Mob-2 loci are located in the proximal portion of chromosome 6 , as the D6Nds4 locus, which is 39 centimorgans distal to D6Mitl, showed no linkage with plasma cholesterol or subcutaneous fat pads $(P>0.10)$.

\section{Discussion}

We report the analysis, using quantitative trait locus mapping, of a new mouse model for obesity and lipoprotein metabolism. This model consists of a backcross between the strains $M$. spretus and the laboratory strain $\mathrm{C} 57 \mathrm{BL} / 6 \mathrm{~J}$, in which the progeny exhibit a wide range of plasma lipoprotein levels (severalfold) as well as carcass lipid percent (from $1 \%$ to $\sim 50 \%$ of total carcass weight). The evidence for genetic loci contributing to plasma cholesterol on chromosomes 6 and 7 is very strong, with LOD scores of 5.6 and 5.8, respectively. Thus, the ratio of the likelihood of linkage to the likelihood of no linkage is considerably $>100,000: 1$ in both cases, and no other LOD scores for plasma total cholesterol $>3.0$ were observed. It has been estimated that, in the mouse, a LOD score of 2.7 is significant (3). As discussed below, neither of these loci contain previously mapped genes likely to contribute to lipoprotein levels. The chromosome 7 locus also determines the percent carcass lipid (LOD score 3.8), suggesting that a common gene contributes to both traits, providing a potential link between obesity and susceptibility to CAD. The chromosome 6 locus, on the other hand, did not show linkage to carcass lipid, although a potential association with subcutaneous fat pad weight was observed.

The chromosome 6 and 7 loci do not correspond to previously mapped genes likely to participate in lipoprotein metabolism. Such genes include those encoding the major apolipoproteins (apo A-I, A-II, A-IV, B, C-I, C-II, C-III, D, E), lipoprotein receptors (the LDL receptor, the LDL receptor-related protein, and an HDL binding protein), enzymes modulating lipid metabolism (hepatic lipase, lipoprotein lipase, lecithin-cholesterol acyl transferase, hormone sensitive lipase, pancreatic lipase, carboxyl ester lipase), and enzymes involved in sterol synthesis (3-hydroxy-3-methylglutary-CoA reductase and synthase). This is not surprising, since it is likely that only a subset of the genes important in regulating lipoprotein levels have been identified using biochemical approaches. For example, the transcription factors controlling the expression of the above structural proteins and enzymes remain largely unknown. The identification of the genes on chromosomes 6 and 7 can now be

Table IV. Comparison of Plasma Cholesterol and a Subcutaneous (Femoral) Fat Pad at the D6Mit1 Locus

\begin{tabular}{|c|c|c|c|c|}
\hline \multirow[b]{2}{*}{ Trait } & \multicolumn{2}{|c|}{ Statistics by genotype, males } & \multicolumn{2}{|c|}{ Statistics by genotype, females } \\
\hline & BB & SB & BB & SB \\
\hline \multirow[t]{2}{*}{ Total cholesterol (mg/dl) } & $65 \pm 2.6$ & $77 \pm 2.6^{*}$ & $61 \pm 2.2$ & $70 \pm 2.5$ \\
\hline & $n=50$ & $n=51$ & $n=65$ & $n=52$ \\
\hline \multirow[t]{2}{*}{ HDL cholesterol (mg/dl) } & $50 \pm 2.3$ & $59 \pm 2.3$ & $44 \pm 2.0$ & $50 \pm 2.2$ \\
\hline & $n=50$ & $n=51$ & $n=65$ & $n=52$ \\
\hline \multirow[t]{2}{*}{ LDL + VLDL cholesterol (mg/dl) } & $15 \pm 1.7$ & $19 \pm 1.7$ & $17 \pm 1.5$ & $21 \pm 1.7$ \\
\hline & $n=50$ & $n=51$ & $n=65$ & $n=52$ \\
\hline \multirow[t]{2}{*}{ Subcutaneous fat pad (g) } & $0.32 \pm 0.13$ & $0.80 \pm 0.13^{\ddagger}$ & $0.27 \pm 0.11$ & $0.70 \pm 0.15^{\ddagger}$ \\
\hline & $n=20$ & $n=22$ & $n=32$ & $n=16$ \\
\hline
\end{tabular}

Data are age adjusted means \pm SE. ANOVA: SB vs. BB, ${ }^{*} P<0.0014,{ }^{\ddagger} P<0.025$. 
further pursued by the construction of congenic strains in which the loci are transferred by breeding onto common backgrounds. This will allow detailed chromosomal mapping and positional cloning.

The association between obesity, lipoprotein metabolism, and CAD is of considerable interest. Some evidence suggests that metabolic changes in adipose tissue may underlie the association. For example, it has been hypothesized that an excess release of FFA from adipose cells may increase hepatic synthesis of triglycerides and VLDL, which may in turn increase the predisposition to CAD (38-40). The release of FFA may be mediated by insulin resistance, which could affect lipolysis of VLDL by lipoprotein lipase (14). There is also evidence for a role of glucocorticoids in FFA release and VLDL synthesis (15). Obesity in BSB mice is associated both with insulin resistance and with abnormalities in glucocorticoid metabolism (32). Our results with the chromosome 6 and 7 loci, indicating a larger effect on VLDL and LDL than HDL are consistent with mediation by insulin resistance and/or glucocorticoids.

The chromosome 6 and 7 loci occur near mutations resulting in extreme obesity and diabetes. Chromosome 7 contains the $t u b b y$ ( $t u b$ ) and Adipose genes while chromosome 6 contains the $o b$ gene. This raises the possibility that alleles of these genes may contribute to the obesity traits in this model. The tub gene is $\sim 1$ centimorgan proximal to D7Mit8 (GBASE; The Jackson Laboratory, 1992) and thus is 10 centimorgans proximal to D7Ucla1. The estimated LOD score for carcass lipid percent at the $t u b$ locus is 3.2 , thus placing $t u b$ within the 90\% confidence interval for Mob-1 and Chol-1. The Adipose gene is distal to $D 7 N d s 4$ and thus is clearly distinct from $M o b-1$ (GBASE; The Jackson Laboratory, 1992). The $o b$ gene on chromosome 6 is $\sim 4$ centimorgans from D6Mit1 and thus occurs within the $90 \%$ confidence interval of both the Mob-2 and Chol-2 genes. Mice homozygous for the $o b$ mutation also have elevated (almost twofold) total cholesterol over the background strain (41). Although total cholesterol levels in mice heterozygous for the $t u b b y$ or obese mutations are not significantly different from the C57BL/6J background strain (41), neither is body weight elevated in those animals. The possibility that variations of the $t u b b y$ and obese genes are involved in the BSB traits is of interest, since it would imply that variants of these genes could contribute to multigenic obesity, and thus could be involved in human obesity.

It is also of interest that, whereas the $M o b-1$ locus determines percent carcass lipid and strongly modulates the sizes of all four fat pads examined, to approximately the same extent, the $M o b-2$ locus affects only the subcutaneous (femoral) fat pads lying on the outer thigh. Human studies have clearly established genetic and sexual differences in the distribution of body fat (42). For example, males tend to accumulate fat in the abdomen, whereas females tend to accumulate fat on the thighs (11). Such differences in fat distribution appear to contribute independently to lipoprotein metabolism and risk of CAD. Thus, in humans, abdominal adipose tissue mass predicts HDL cholesterol levels independent of body mass index (43, 44). It has been suggested that body fat distribution differences may explain, in part, the striking sex differences in CAD (45). The effects of $M o b-1$ and $M o b-2$ provide the clearest known example of genetic determination of fat distribution.

The obesity observed in the BSB mice is likely to result in part from interactions of alleles derived from the C57BL/6J and $M$. spretus parental strains, since neither parental strain exhibits the dramatic obesity observed among the backcross progeny. In this regard, the BSB model resembles the Wellesley mouse model of obesity and diabetes in which F1 hybrids of C3Hf and I strains are more prone to diabetes than either parental strain (46). Since the chromosome 6 and 7 loci explain a small fraction of the total variance of body fat and lipoprotein levels, additional genetic loci undoubtedly contribute to the traits. These may be revealed as additional animals and markers are typed.

The number of quantitative trait loci that can be identified for any given trait is limited, in part, by both genetic and assay variance. For instance, the ability to identify loci underlying fatty streak formation by quantitative trait locus mapping may be limited due to the large variances observed in fatty streak assays of inbred mouse stains (35). In contrast, assays for total and HDL cholesterol have relatively small variances, since the standard deviations for these assays are $<20 \%$ of the mean for C57BL/6J mice ( $n=25$, data not shown). Assays of obesity in mice also display relatively small variances in body weight measurements within inbred strains (47). We have compared the variance of carcass lipid percent and serum cholesterol levels in C57BL/6J and BSB mice. Contemporaneous measurements of carcass lipid percent and serum cholesterol levels were made in C57BL/6J $(n=25)$ and BSB mice $(n=235)$. Variances were over fourfold higher for carcass lipid, 44\% higher for total cholesterol, and 93\% higher for LDL cholesterol in BSB mice than in C57BL/6J (data not shown). These results suggest that the increased variance of BSB mice is due to increased genetic variance.

In conclusion, our results provide strong evidence that mouse chromosomes 6 and 7 contain genes with important effects on plasma cholesterol levels and fat accumulation. The coincidence, on chromosome 7, of loci determining both traits is of particular interest and may be relevant to the link between obesity and CAD. These data provide "candidate loci" that should be tested for linkage to obesity and lipoprotein levels in human families. Chol-1 and Mob-1 loci on distal mouse chromosome 7 are homologous to regions of human chromosomes 10,11 , and 16, while the human homologues of Chol-2 and $M o b-2$ are probably located on chromosome $7 \mathrm{q} 31-\mathrm{q} 32$, since the met proto-oncogene ( $M e t$ ) locus, which maps to the same position as D6Mitl is homologous to human chromosome 7q31-q32.

\section{Acknowledgments}

We thank Margarete Mehrabian, Kong-yuan He, Anh Diep, Yu-Rong $\mathrm{Xia}$, and Ping-Zi Wen for invaluable help in the analysis of genetic markers, Louis Tieu for assistance with body composition measurements, Craig Laughton and Dianne Ruddle (Syntex Corporation, Palo Alto, CA) for analysis of the plasma lipids and Richard Hyman (Palo Alto Institute for Molecular Medicine) for help in the analysis of certain genetic markers.

This work was supported in part by National Institutes of Health grants HL-28481 and DK45066 and by a grant from the Medical Faculty Women's Association of the University of Southern California, School of Medicine (to J. S. Fisler).

\section{References}

1. Mehrabian, M., and A. J. Lusis. 1992. Genetic markers for studies of atherosclerosis and related risk factors. In Monographs in Human Genetics: Molecular Genetics of Coronary Artery Disease. A. J. Lusis, J. I. Rotter, and R. S. Sparkes, editors. Karger, Basel. 363-418. 
2. Breslow, J. L. 1992. The genetic basis of lipoprotein disorders. Introduction and overview. J. Intern. Med. 231:627-631.

3. Lander, E. S., and D. Botstein. 1989. Mapping Mendelian factors underlying quantitative traits using RFLP linkage maps. Genetics. 121:185-199.

4. Warden, C. H., A. Daluiski, and A. J. Lusis. 1992. Identification of new genes contributing to atherosclerosis: the mapping of genes contributing to complex disorders in animal models. In Monographs in Human Genetics: Molecular Genetics of Coronary Artery Disease. A. J. Lusis, J. I. Rotter, and R. S. Sparkes, editors. Karger, Basel. 419-441.

5. Todd, J. A., and S. C. Bain. 1992. A practical approach to identification of susceptibility genes for IDDM. Diabetes 41:1029-1034.

6. Jacob, H. J., K. Lindpaintner, S. E. Lincoln, K. Kusumi, R. K. Bunker, Y. P. Mao, D. Ganten, V. J. Dzau, and E. S. Lander. 1991. Genetic mapping of a gene causing hypertension in the stroke-prone spontaneously hypertensive rat. Cell. 67:213-224.

7. Hilbert, P., K. Lindpaintner, J. S. Beckmann, T. Serikawa, F. Soubrier, C. Dubay, P. Cartwright, B. De Gouyon, C. Julier, S. Takahasi, et al. 1991. Chromosomal mapping of two genetic loci associated with blood-pressure regulation in hereditary hypertensive rats. Nature (Lond.). 353:521-529.

8. Karathanasis, S. K. 1992. Lipoprotein metabolism: high-density lipoprotein. In Monographs in Human Genetics: Molecular Genetics of Coronary Artery Disease. A. J. Lusis, J. I. Rotter, and R. S. Sparkes, editors. Karger, Basel. 140 171.

9. Miller, N. E. 1987. Associations of high-density lipoprotein subclasses and apolipoproteins with isochemic heart disease and coronary atherosclerosis. $\mathrm{Am}$. Heart J. 113:589-597.

10. Larsson, B., P. Björntorp, and G. Tibblin. 1981. The health consequences of moderate obesity. Int. J. Obes. 5:97-116.

11. Kissebah, A. H., D. S. Freedman, and A. N. Peiris. 1989. Health risks of obesity. Med. Clin. North Am. 73:111-138.

12. Bray, G. A., M. B. Davidson, and E. J. Drenick. 1972. Obesity: a serious symptom. Ann. Intern. Med. 77:779-795.

13. Bierman, E. L., and J. D. Brunzell. 1992. Obesity and atherosclerosis. In Obesity. P. Bjorntorp and B. N. Brodoff, editors. J. B. Lippincott Co., Philadelphia. 512-516.

14. Frayn, K. N., and S. W. Coppack. 1992. Insulin resistance, adipose tissue and coronary heart disease. Clin. Sci. (Lond.). 82:1-8.

15. Brindley, D. N., and Y. Rolland. 1989. Possible connections between stress, diabetes, obesity, hypertension and altered lipoprotein metabolism that may result in atherosclerosis. Clin. Sci. (Lond.). 77:453-461.

16. Björntorp, P. 1991. Visceral fat accumulation: the missing link between psychosocial factors and cardiovascular disease? J. Intern. Med. 230:195-201.

17. Heizmann, C., T. Kirchgessner, P. O. Kwiterovich, J. A. Ladias, C. Derby, S. E. Antonarakis, and A. J. Lusis. 1991. DNA polymorphism haplotypes of the human lipoprotein lipase gene: possible association with high density lipoprotein levels. Hum. Genet. 86:578-584.

18. Coleman, D. L., and E. M. Eicher. 1990. Fat (fat) and tubby (tub): two autosomal recessive mutations causing obesity syndromes in the mouse. $J$ Hered. 81:424-427.

19. Coleman, D. L. 1978. Obese and diabetes: two mutant genes causing diabetes-obesity syndromes in mice. Diabetologia. 14:141-148.

20. Wallace, M. E., and F. M. MacSwiney. 1979. An inherited mild middleaged adiposity in wild mice. J. Hyg. 82:309-317.

21. Truett, G. E., N. Bahary, J. M. Friedman, and R. L. Leibel. 1991. Rat obesity gene fatty (fa) maps to chromosome 5: evidence for homology with the mouse gene diabetes (db). Proc. Natl. Acad. Sci. USA. 88:7806-7809.

22. Bielschowsky, M., and F. Bielschowsky. 1953. A new strain of mice with hereditary obesity. Proc. Otago Medical School. 31:29-31.

23. Nakamura, M. A. 1962. A diabetic strain of the mouse. Proc. Jpn. Acad. $38: 348-352$

24. Bultman, S. J., E. J. Michaud, and R. P. Woychik. 1992. Molecular characterization of the mouse agouti locus. Cell. 71:1195-1204.

25. Camus, M. C., R. Aubert, F. Bourgeois, J. Herzog, A. Alexiu, and D. Lemonnier. 1988. Serum lipoprotein and apolipoprotein profiles of the genetically obese ob/ob mouse. Biochim. Biophys. Acta. 961:53-64.

26. Schnitzer-Polokoff, R., C. Margetin, A. Abdollahi, and O. Tulp. 1989
Effects of phenotype, sex, and diet on plasma lipids in LA/N-cp rats. Proc. Soc. Exp. Biol. Med. 191:326-331.

27. Love, J. M., A. M. Knight, M. A. McAleer, and J. A. Todd. 1990. Towards construction of a high resolution map of the mouse genome using PCR-analysed microsatellites. Nucleic Acids Res. 18:4123-4130.

28. Cornall, R. J., T. J. Aitman, C. M. Hearne, and J. A. Todd. 1991. The generation of a library of PCR-analyzed microsatellite variants for genetic mapping of the mouse genome. Genomics. 10:874-881.

29. Dietrich, W., H. Katz, S. E. Lincoln, H.-S. Shin, J. Friedman, N. C. Dracopoli, and E. S. Lander. 1992. A genetic map of the mouse suitable for typing intraspecific crosses. Genetics. 131:423-447.

30. Lander, E. S., P. Green, J. Abrahamson, A. Barlow, M. J. Daly, S. E. Lincoln, and L. Newburg. 1987. MAPMAKER: an interactive computer package for constructing primary genetic linkage maps of experimental and natural populations. Genomics. 1:174-181.

31. Paterson, A. H., E. S. Lander, J. D. Hewitt, S. Peterson, S. E. Lincoln, and S. D. Tanksley. 1988. Resolution of quantitative traits into Mendelian factors by using a complete linkage map of restriction fragment length polymorphisms. Nature (Lond.). 335:721-726.

32. Fisler, J. S., C. H. Warden, M. J. Pace, and A. J. Lusis. 1993. BSB: a new mouse model of multigenic obesity. Obesity Res. 1:271-280.

33. Paigen, B., D. Mitchell, K. Reue, A. Morrow, A. J. Lusis, and R. C. LeBoeuf. 1987. Ath-1, a gene determining atherosclerosis susceptibility and high density lipoprotein levels in mice. Proc. Natl. Acad. Sci. USA. 84:3763-3767.

34. McGowan, M. W., J. D. Artiss, D. R. Strandbergh, and B. Zak. 1983. A peroxidase-coupled method for the colorimetric determination of serum triglycerides. Clin. Chem. 29:538-542.

35. Mehrabian, M., J.-H. Qiao, R. Hyman, D. Ruddle, C. Laughton, and A. J. Lusis. 1993. Influence of the ApoA-II gene locus on HDL levels and fatty streak development in mice. Arterioscler. Thromb. 13:1-10.

36. Lusis, A. J., B. A. Taylor, D. Quon, S. Zollman, and R. C. LeBoeuf. 1987 Genetic factors controlling structure and expression of apolipoproteins $B$ and $E$ in mice. J. Biol. Chem. 262:7594-7604.

37. Church, G. M., and W. Gilbert. 1984. Genomic sequencing. Proc. Natl. Acad. Sci. USA. 81:1991-1995.

38. Havel, R. J., J. P. Kane, E. O. Balasse, N. Segel, and L. V. Basso. 1970. Splanchnic metabolism of free fatty acids and production of triglycerides of very low density lipoproteins in normotriglyceridemic and hypertriglyceridemic humans. J. Clin. Invest. 49:2017-2035.

39. Austin, M. A. 1991. Plasma triglyceride and coronary heart disease. Arterioscler. Thromb. 11:2-14.

40. Reaven, G. M., and C. E. Mondon. 1984. Effect of in vivo plasma insulin levels on the relationship between perfusate free fatty acid concentration and triglyceride secretion by perfused rat livers. Horm. Metab. Res. 16:230-232.

41. Nishina, P. M., S. Lowe, J. Wang, and B. Paigen. 1993. Characterization of plasma lipids in genetically obese mice; the mutants obese, diabetes, fat, tubby and lethal yellow. Metab. Clin. Exp. In press.

42. Himes, J. H., C. Bouchard, and A. M. Pheley. 1991. Lack of correspondence among measures identifying the obese. Am. J. Prev. Med. 7:107-111.

43. Pouliot, M.-C., J.-P. Després, A. Nadeau, S. Moorjani, D. Prudhomme, P. J. Lupien, A. Tremblay, and C. Bouchard. 1992. Visceral obesity in men: associations with glucose tolerance, plasma insulin, and lipoprotein levels. Diabetes. 41:826-834.

44. Després, J.-P., A. Tremblay, L. Pérusse, C. Leblanc, and C. Bouchard. 1988. Abdominal adipose tissue and serum HDL-cholesterol: association independent from obesity and serum triglyceride concentration. Int. J. Obes. 12:1-13.

45. Larsson, B., C. Bengtsson, P. Björntorp, L. Lapidus, L. Sjöström, K. Svärdsudd, G. Tibblin, H. Wedel, L. Welin, and L. Wilhelmsen. 1992. Is abdominal body fat distribution a major explanation for the sex difference in the incidence of myocardial infarction? Am. J. Epidemiol. 135:266-273.

46. Cahill, G. F., E. E. Jones, V. Lauris, J. Steinke, and J. S. Soeldner. 1967 Studies of experimental diabetes in the Wellesley hybrid mouse. II. Serum insulin levels and response of peripheral tissues. Diabetologia. 3:171-174

47. West, D. B., C. N. Boozer, D. L. Moody, and R. L. Atkinson. 1992. Dietary obesity in nine inbred mouse strains. Am. J. Physiol. (Regul. Integr. Comp. Physiol.) 262:R1025-R1032. 